\title{
Geographical distribution, a risk factor for the incidence of lupus nephritis in China
}

\author{
Qingjun Pan, Yaning Li, Ling Ye, Zhenzhen Deng, Lu Li, Yongmin Feng, Weijing Liu and Huafeng Liu*
}

\begin{abstract}
Background: Geographical variation in lupus nephritis epidemiology may indicate important environmental factors contributions to the etiology of lupus nephritis. This paper first describes the epidemiology of biopsy-proven lupus nephritis in China by performing a systematic literature review and the possible social-environmental influential factors.

Methods: The keywords "lupus nephritis", "renal biopsy" and "systemic lupus erythematous" were searched in the three largest Chinese electronic databases and Medline/PubMed. The data of the patients with biopsy-proven lupus nephritis were extracted. The possible environmental influential factors including the population density, ethnic group populations, the ratio of females to males, the average sunshine per year, annual average temperature and annual relative humidity, in different regions of China were analyzed.
\end{abstract}

Results: Forty-one study centers with 34574 renal disease patients, and 3699 lupus nephritis patients met the inclusion criteria. Lupus nephritis accounts for $2.37 \%$ to $25 \%$ of all renal disease and $27.2 \%$ to $80.65 \%$ of renal disease associated with secondary glomerular diseases. The male-to-female ratio is approximately 1:5 in lupus nephritis patients. The included period is predominantly from 1995 to 2010. The proportion ratio of biopsy-proven lupus nephritis in all renal disease or in secondary glomerular disease significantly increased with decreasing latitude from the north to the south part of China. The population is predominantly Han Chinese.

Conclusions: Geographical distribution appears to be a risk factor for the incidence of biopsy-proven LN in China.

Keywords: Biopsy, Lupus nephritis, Geographical distribution, China

\section{Background}

Environmental and genetic factors interact to result in the development of systemic lupus erythematous (SLE) [1]. Many epidemiologic studies of SLE have been undertaken worldwide $[2,3]$ and have detailed worldwide SLE epidemiology, considering the effects of gender, race, and age on presentation and mortality $[4,5]$.

Renal involvement is common in SLE patients, although accurate current data and systematic investigation of the epidemiology of lupus nephritis (LN) worldwide are largely lacking [6]. The epidemiology of LN based on a selected population and the diagnostic criteria for defining SLE was reported [7]. The LN cumulative incidence is lower in Caucasians (14\%) with SLE compared with Asians (55\%), African lineages (51\%) and Hispanics (43\%)

\footnotetext{
* Correspondence: hf-liu@263.net

Institute of Nephrology, Affiliated Hospital of Guangdong Medical College, Zhanjiang, PR 524001, China
}

with SLE $[8,9]$. LN is associated with more severe renal involvement in the patients from African lineage, Hispanics and Asian populations [9-14]. Also, LN is more likely to be associated with severe nephritis in children and less likely to be associated with severe neuritis in the elderly [15].

These reviews included very few studies conducted in China. There is no systematic investigation of the epidemiology of LN in China. Reports of the incidence of biopsy-proven LN in different geographical regions of China have yielded different results, possibly because the vast territory and a huge population of China results in marked differences in environmental and genetic risk factors for LN. Research papers published in Chinese or other languages are yet to be reviewed to determine the epidemiology of biopsy-proven LN in China.

In this study, we examined the association between geographic distribution and the epidemiology of biopsy- 
proven LN in China by summarizing 41 studies on LN disease published in different parts of China. We found that LN may be more prevalent in southern China.

\section{Methods}

Search strategy: "Lupus nephritis", "renal biopsy" and "systemic lupus erythematous" were the key words searched in the three largest Chinese electronic databases including the China National Knowledge Infrastructure (CNKI, www.cnki.net, inception 1994), Wan Fang (www.wanfang data.com.cn, inception 1982), and $\mathrm{Vi} P u$ (www.cqvip.com, inception 1989) The identical keywords with "Chinese" and "China" were searched in the database of Medline/ PubMed for papers published from the inception of the databases to July 2013. The data of the patients with lupus nephritis diagnosed by renal biopsy were extracted and analyzed. The geographical distributions of the cities in which the study centers were located were found with Google Maps. We reviewed each paper with inclusion and exclusion criteria.

Inclusion and exclusion criteria: The inclusion criteria for the analyzed papers are as follows: (1) the location of the study centers are in mainland China; (2) the number of patients with biopsy-proven renal diseases was more than 100 cases in each paper; (3) the define of LN was by renal biopsy. (4) The diagnostic criteria for the studies are as follows: the classification of each patient's pathological histological type of renal disease was according to the WHO criteria for the histological classification of glomerular defined in 1982 [16] and revised in 1995 [17] and the criteria of the ISN/RPS. The exclusion criteria for this study are papers that do not meet any items of (1), (2), (3) and (4).

Data Analysis: The characteristics of the analyzed studies included the geographical distribution of the study centers, the research period, and the ratio of the number of females to males for all of the renal biopsies or the LN group, if provided. Pearson's correlation coefficients were calculated to assess the linear association between the proportions of the biopsy-proven LN in all renal diseases or in secondary glomerular diseases (SGD) and the geographical distribution of the study centers. The calculations were performed with SPSS (14.0) software, and statistical significance was established at $\mathrm{p}<0.05$.

The possible influential factors: To investigate the possible factors that are influential on geographical variation in the epidemiology of biopsy-proven lupus nephritis in China, we investigated the population density, ethnic group populations, the ratio of females to males, the average sunshine per year, annual average trmperature and annual relative humidity in different regions of China.

\section{Results}

The characteristics of the study centers included in the analyses

Our literature searches yielded 41 studies that met the study validation criteria (Table 1) [18-58], which all originate from the Chinese databases. All of the selected studies were retrospective and included 34574 biopsyproven renal disease patients and 3699 biopsy-proven LN patients. The World Health Organization 1995 Classification System (issued in 1982) is the most commonly used criteria for patients who had a renal biopsy. The study centers were normally distributed in China (Figure 1A) and most of the study period was from 1995 to 2010 (Figure 1B).

Based on the forty-one studies, LN was the most common SGD found by percutaneous kidney biopsy and accounted for $2.37 \%$ to $25 \%$ of all biopsy-proven renal diseases and $27.2 \%$ to $80.65 \%$ of renal disease biopsies performed for secondary causes of glomerular disease.

The ratio of male-to-female in the biopsy-proven LN patients was approximately 1:5 based on the provided data (Figure 1D) [20,27,36,49,54,58]. and approximately $1: 1$ in all biopsy-proven renal diseases (Figure 1C) [18-58].

\section{The correlation between the geographical distribution and the proportion of biopsy-proven LN}

The proportion of biopsy-proven LN in all biopsyproven renal diseases $(r=0.524 ; \mathrm{P}<0.001)$ (Figure 2A) and in secondary glomerular diseases (SGD) $(r=0.460$; $\mathrm{P}<0.001$ ) (Figure $2 \mathrm{~B}$ ) significantly increased in response to the decreasing geographic latitude from the northern part to the southern part of China, but there was no significant correlation with the change in the geographic longitude (all P > 0.05) (Figure 2C, 2D).

\section{The possible influential factors}

For the 41 studies, the population density was 400-700 people per $\mathrm{Km}^{2}$ (Figure 3A) in 2000, and the population is predominantly Han Chinese (Figure $3 \mathrm{~B}$ ). Figure $3 \mathrm{C}$ showed that there was no significant correlation between the geographical latitude and the ratio of female to male (extracted from China 2000 census) in the population in the southern and northern latitudes of China. In China, the annual sunshine duration ranges from less than 1100 hours in parts of Sichuan and Chongqing to over 3400 hours in northwestern Qinghai. The seasonal patterns in sunshine vary considerably by region, but overall, the north and the Tibetan Plateau are sunnier than the south of the country (Figure 3D). But interestingly, for the annual average temperature and annual relative humidity reported by China Meterological Administration, its guadually increased from the northern to southern latitudes of China, which maybe possible influential factors 
Table 1 Basic information of the 41 studies which met the study validation criteria

\begin{tabular}{|c|c|c|c|c|c|c|c|c|c|c|c|c|}
\hline \multirow[t]{2}{*}{ No } & \multirow{2}{*}{$\begin{array}{l}\text { Ref. (First author, } \\
\text { Ref, Year) }\end{array}$} & \multicolumn{2}{|c|}{ Distribution $\left(^{\circ}\right)$} & \multicolumn{4}{|c|}{ Biopsy-proven LN } & \multicolumn{5}{|c|}{ All biopsy-proven renal diseases } \\
\hline & & Lat. & Long. & Cases & $\begin{array}{l}\text { (LN/all renal } \\
\text { diseases) } \times 100 \%\end{array}$ & $(\mathrm{LN} / \mathrm{SGD}) \times 100 \%$ & $\begin{array}{l}\text { Sex } \\
\text { (F/M Ratio) }\end{array}$ & Cases & Begin & End & $\begin{array}{l}\text { Sex } \\
\text { (F/M Ratio) }\end{array}$ & Age (average \pm S.D, range) \\
\hline 1 & Xu YZ [18] 2009 & 21.11 & 110.30 & 322 & 19.77 & 65.04 & & 1627 & 1999 & 2007 & 1.01 & $30.7 \pm 15.1$ \\
\hline 2 & Luo Q [19] 2008 & 22.35 & 113.46 & 76 & 12.40 & 60.80 & & 615 & 2000 & 2007 & 1.00 & $F(33.1 \pm 7.8), M(33.56 \pm 13.3)$ \\
\hline 3 & Mo WG [20] 2004 & 22.47 & 108.20 & 309 & 20.61 & 80.26 & 5.44 & 1499 & 1999 & 2004 & 1.07 & 30.52 \\
\hline 4 & Zhong HB [21] 2007 & 26.02 & 117.36 & 95 & 10.41 & 53.07 & & 913 & 1993 & 2006 & 0.70 & $30.12 \pm 15.37$ \\
\hline 5 & Chen JY [22] 2008 & 26.02 & 119.18 & 31 & 11.52 & 62.00 & & 269 & 1998 & 2007 & 0.78 & $11-68$ \\
\hline 6 & Zhu CL [23] 2003 & 26.34 & 106.42 & 25 & 25.00 & 80.65 & & 100 & 1999 & 2002 & 1.70 & $40.7 \pm 28.3$ \\
\hline 7 & Li SR [24] 2004 & 28.00 & 119.31 & 12 & 10.62 & 46.15 & & 113 & 1996 & 2004 & 1.05 & $36,14-73$ \\
\hline 8 & Ke YJ [25] 2004 & 28.00 & 121.20 & 20 & 17.70 & & & 113 & 2000 & 2002 & 0.61 & 32.8 \\
\hline \multirow[t]{2}{*}{9} & Xiang XQ [26] 2005 & 28.12 & 113.00 & 87 & 7.18 & & & 1211 & 1989 & 2004 & & 35.16 (1989-1997) \\
\hline & & & & & & & & & & & & $35.65(2000-2004)$ \\
\hline 10 & Sun T [27] 2006 & 29.33 & 106.32 & 46 & 9.41 & 54.76 & 4.75 & 489 & 2004 & 2005 & 1.39 & $32 \pm 16$ \\
\hline 11 & Shi XD [28] 2003 & 30.15 & 119.14 & 82 & 12.26 & 55.78 & & 669 & 1992 & 2001 & 1.42 & $9-79$ \\
\hline 12 & Xu YC [29] 2005 & 30.39 & 104.05 & 15 & 11.00 & 53.57 & & 140 & 2000 & 2003 & 0.94 & $40.5,13-70$ \\
\hline 13 & Liu K [30] 2007 & 31.12 & 121.29 & 21 & 19.63 & 63.64 & & 107 & 2003 & 2005 & 1.55 & 32.9 \\
\hline 14 & Yu JP [31] 2000 & 31.12 & 121.29 & 17 & 9.60 & & & 177 & 1994 & 1999 & 0.86 & 34.47 \\
\hline 15 & Chen HP [32] 2000 & 31.20 & 118.50 & 1319 & 12.45 & 74.14 & & 10594 & 1979 & 2000 & 0.97 & $31.4 \pm 13$ \\
\hline 16 & Peng YP [33] 2005 & 31.51 & 114.52 & 19 & 10.80 & 67.40 & & 176 & 2000 & 2004 & 1.29 & $38,13-74$ \\
\hline 17 & Wang T [34] 2010 & 32.03 & 118.50 & 44 & 5.47 & 34.92 & & 805 & 2003 & 2008 & 0.98 & $36.12 \pm 16.08$ \\
\hline 18 & Fan YL [35] 1995 & 33.96 & 116.23 & 6 & 5.66 & & & 106 & 1989 & 1992 & 0.58 & $32,13-60$ \\
\hline 19 & Du JL [36] 2006 & 34.15 & 110.54 & 220 & 14.27 & 53.14 & 14.7 & 1542 & 2000 & 2004 & 0.65 & $33.5 \pm 11.8(\mathrm{LN})$ \\
\hline 20 & Shi J [37] 2010 & 34.15 & 110.54 & 6 & 2.37 & 11.76 & & 253 & 2005 & 2008 & 0.85 & $32 \pm 16$ \\
\hline 21 & Wang HX [38] 2007 & 34.16 & 117.11 & 40 & 11.36 & 41.70 & & 352 & 1998 & 2007 & 1.10 & $38 \pm 9.5$ \\
\hline 22 & Li SK [39] 2009 & 34.16 & 117.11 & 59 & 7.94 & 38.82 & 4.36 & 743 & 2005 & 2008 & 0.79 & $30.09 \pm 14.19$ \\
\hline 23 & Wang YT [40] 2010 & 34.44 & 113.53 & 38 & 4.13 & 27.74 & & 919 & 1996 & 2008 & 0.81 & $33.1 \pm 14.1,16-72$ \\
\hline 24 & Zhao ZZ [41] 2005 & 34.44 & 113.42 & 60 & 14.56 & 54.55 & & 412 & 2001 & 2003 & 0.98 & $6-69$ \\
\hline 25 & Li XY [42] 2007 & 34.44 & 114.51 & 9 & 6.25 & 28.10 & & 144 & 1999 & 2004 & 1.18 & $9-72$ \\
\hline 26 & Zhou SY [43] 2008 & 36.03 & 103.49 & 49 & 4.08 & 50.00 & & 1202 & 1994 & 2006 & 0.94 & 31.54 \\
\hline 27 & Zheng CX [44] 2009 & 36.63 & 114.47 & 33 & 7.04 & 31.43 & & 469 & 2000 & 2008 & 0.85 & $34.6,9-78$ \\
\hline 28 & Huo J [45] 2007 & 37.51 & 112.34 & 72 & 5.62 & 27.20 & & 1281 & 1993 & 2006 & 0.77 & $31.6 \pm 13.3,6-74$ \\
\hline 29 & Wang YM [46] 2010 & 38.03 & 115.28 & 14 & 5.22 & 26.92 & & 268 & 2004 & 2009 & 0.97 & $35 \pm 18,13-76$ \\
\hline 30 & Zhao CX [47] 2009 & 38.03 & 116.83 & 6 & 3.16 & 20.00 & & 190 & 2004 & 2006 & 0.92 & $30.3,11-67$ \\
\hline
\end{tabular}


Table 1 Basic information of the 41 studies which met the study validation criteria (Continued)

\begin{tabular}{|c|c|c|c|c|c|c|c|c|c|c|c|c|}
\hline 31 & Ding XG [48] 2008 & 39.36 & 118.11 & 21 & 5.80 & 37.49 & & 362 & 2005 & 2007 & 0.88 & $34.3 \pm 8.2,11-70$ \\
\hline 32 & Zhang YP [49] 2001 & 39.54 & 116.28 & 142 & 7.27 & 37.10 & 4.46 & 1954 & 1987 & 1999 & 0.50 & $33.2 \pm 13,15-73$ \\
\hline 33 & Wang WX [50] 1996 & 39.54 & 116.28 & 13 & 12.50 & 38.24 & & 104 & 1989 & 1994 & 0.51 & $13-70$ \\
\hline 34 & Liu WX [51] 2008 & 39.54 & 116.28 & 11 & 11.00 & 50.00 & & 100 & 2002 & 2008 & 0.82 & $36.2 \pm 14.3,6-65$ \\
\hline 35 & Hou XY [52] 2009 & 40.48 & 111.41 & 10 & 4.61 & 71.43 & & 217 & 2004 & 2009 & 0.75 & $31.8 \pm 10.6,9-70$ \\
\hline 36 & Wang CH [53] 2009 & 40.48 & 116.21 & 40 & 15.27 & 48.78 & & 262 & 2005 & 2008 & 0.76 & $37.82 \pm 15.51,12-74$ \\
\hline 37 & Li YQ [54] 2006 & 41.48 & 123.24 & 91 & 7.03 & 48.37 & 7.5 & 1295 & 1997 & 2004 & 0.77 & $3.62 \pm 8.53,8-76$ \\
\hline 38 & Feng W [55] 2008 & 43.46 & 87.36 & 87 & 5.80 & 34.25 & & 1500 & 1993 & 2007 & 0.97 & $31.4 \pm 13,9-70$ \\
\hline 39 & Yue H [56] 2006 & 43.46 & 87.36 & 12 & 5.05 & 41.26 & & 237 & 1999 & 2005 & 0.85 & $35.6 \pm 14,7-74$ \\
\hline 40 & Wang LY [57] 2005 & 43.55 & 125.19 & 53 & 10.60 & 43.09 & & 500 & 1984 & 2004 & 0.66 & $39.8 \pm 3,7-74$ \\
\hline 41 & Jiang GT [58] 2008 & 45.45 & 126.41 & 61 & 11.19 & 64.20 & 5.8 & 545 & 2003 & 2005 & 1.27 & $1.7 \pm 12.6,8-64$ \\
\hline
\end{tabular}

Abbreviation: latitude (Lat.), Longitude (Long.); Femal (F), Male (M), Referance (Ref.), Number (No.). 

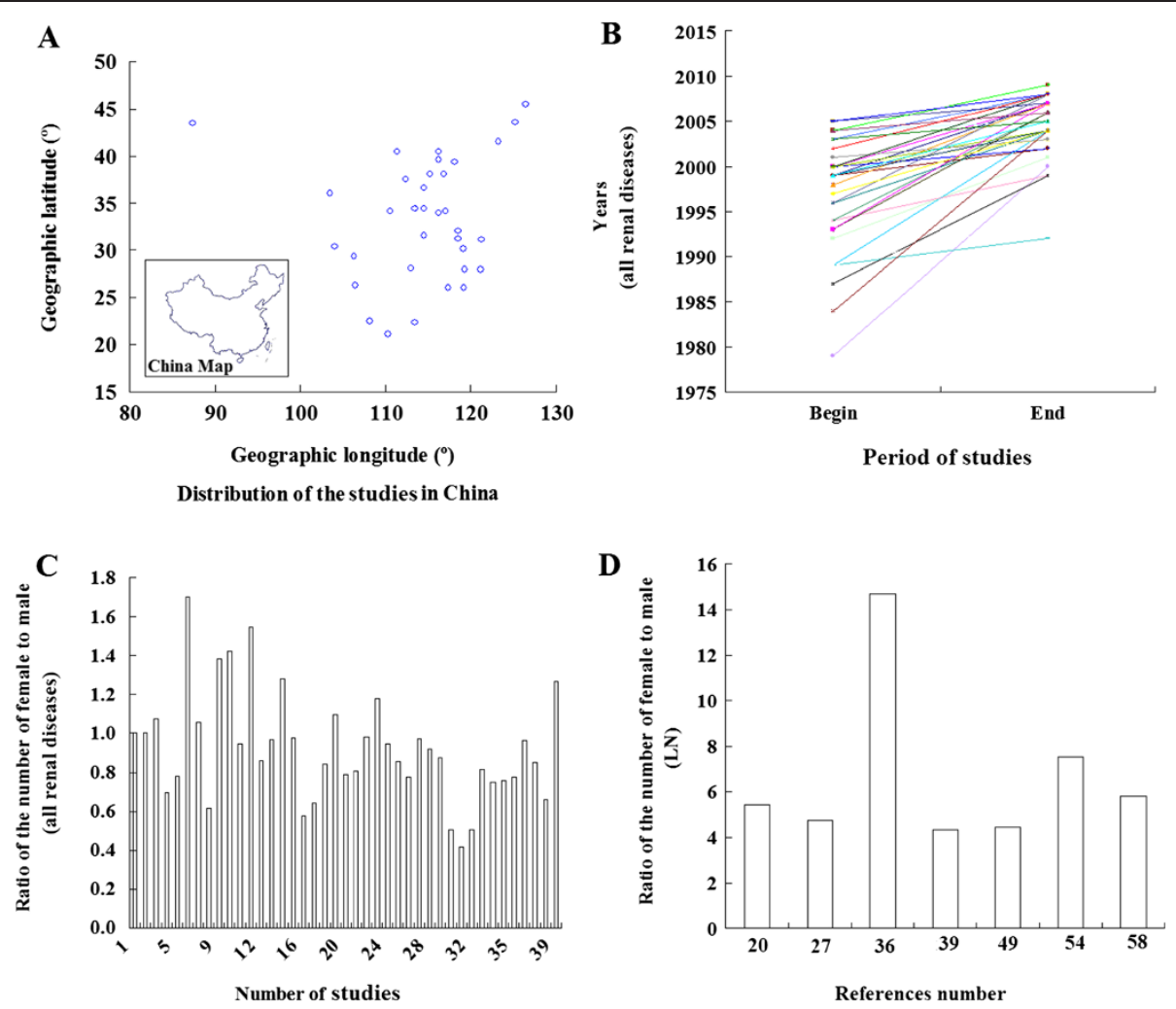

Figure 1 The characteristics of the study centers included in the analyses. The distribution of the studies in China (A), the study period, from the beginning to the end, for all renal diseases (B), the ratio of the number of females to males in all cases of renal disease (C) and the ratio of the number of females to males in LN disease (D).

on the epidemiology of biopsy-proven LN in China (Figure 3E, 3F).

\section{Discussion}

This study is the first to perform a systematic review of the literature to investigate the epidemiology of biopsyproven lupus nephritis in China. The results showed that geographical distribution appears to be a risk factor for the incidence of biopsy-proven LN in China. The proportion of biopsy-proven LN in all biopsy-proven renal diseases and in the secondary glomerular diseases significantly increased with the decreasing geographic latitude from the northern to the southern part of China, but there was no significant correlation with the change of geographic longitude. The lack of difference in longitudes may be because most studies located in a particular longitude band.

A limited amount of data was available regarding the influence of gender, with only seven studies $[20,27,36,39,54,58]$ reporting that the ratio of male-tofemale was approximately 1:5 in biopsy-proven LN patients. As was reported, SLE affects women much more frequently than men, but there is considerable regional variation in the ratio of female: male in SLE patients, e. g., in Curaçao (5:3) [59] in Oman (23:1) [60] and in the
Philippines (23:1) [61]. One of the major target organs in SLE patients is the kidney, and LN is the most common types of secondary glomerular diseases and frequently seen in females $[62,63]$.

There are reports of considerable variation in the ratios of female to male according to different geographical area of the world, and we investigated whether the prevalence of biopsy proven-LN is determined by a higher ratio of females to males in populations living in the southern latitude compared to the northern latitude of China. Also, our results showed that there was no significant correlation between the geographic latitude and the ratio of females to males in the populations living in the southern latitude and the northern latitude in China.

We analyzed the environmental and genetic factor interaction in the epidemiology of biopsy proven-LN in China. In the 41 studies, the population density is predominantly 400-700 people per $\mathrm{Km}^{2}$, and the population is Han Chinese. So, the population density and ethnicity may be not decisive factors for the epidemiology of biopsy proven-LN in China. Another important environmental factor is the annual duration of sunshine that ranges from less than 1100 hours in parts of Sichuan and Chongqing to over 3400 hours in northwestern Qinghai. Seasonal sunshine patterns vary considerably by region, 
A

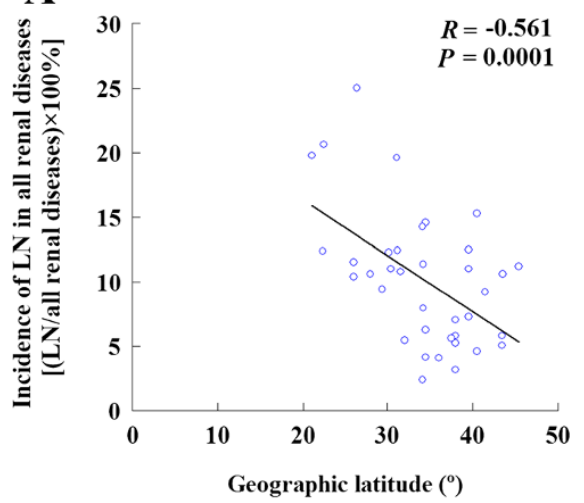

C

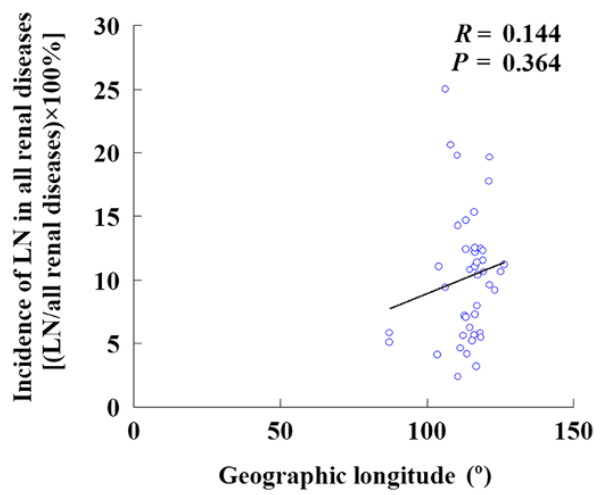

B

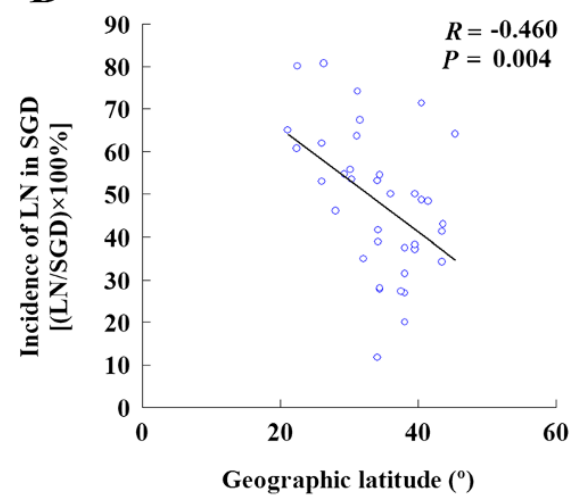

D

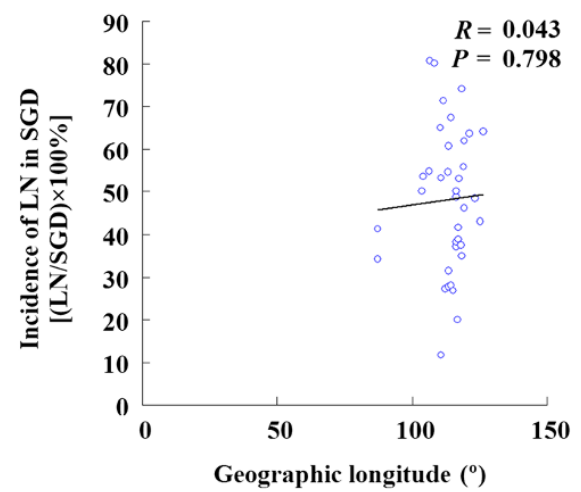

Figure 2 The correlation between the geographical distribution and the proportion of biopsy-proven LN. The incidence of LN in all renal diseases was correlated with the geographic latitude (A), the incidence of LN in secondary glomerular diseases (SGD) correlated with geographic longitude (B), the incidence of LN in all renal diseases correlated with the geographic latitude (C) and the incidence of LN in secondary

glomerular diseases (SGD) with the geographic longitude (D).

but overall, the north and the Tibetan Plateau are sunnier than the south of China, thus the annual sunshine duration may be not decisive factors.

Ultraviolet (UV) radiation, a well-recognized inducement of SLE, but UV radiation-measuring networks are extremely scarce, particularly in China [64]. Also, numerous factors can influence UV radiation, including cloud characteristics, solar zenith angles, total ozone, aerosol pollution and surface albedo. Wei et al [65] reported that the summer UV irradiance has increased significantly from Central China to the northern and western parts of China, especially in Central China near Chongqing, Shanxi, and Hubei provinces; whereas the UV irradiance has decreased significantly in the southern part of China, especially in South China. In July, when UV irradiance is at its maximum and hence when the most serious potential damage may happen, the results indicate an increase in the UV irradiance in Central China and the Yangtze River-Huaihe River valley and a decrease in South China and the eastern part of North China. Thus the influence of ultraviolet radiation on geographical distribution of biopsy-proven LN in China also may be not decisive factors which maybe need to be further investigated.

However, the annual average temperature and annual relative humidity reported by China Meterological Administration, maybe influential factors on the epidemiology of biopsy-proven LN in China. According to a report about the characteristics of seasonal distribution of active SLE and the influences of meteorological factors including temperature and humidity on active SLE in the city of Zhanjiang which is located in the southernmost continent of China, Liu et al found that active SLE has the characteristics of seasonal distribution and is associated with temperature but not related to mean humidity [66].

The majority of LN patients in China receive health care from a doctor near them, and in the 41 studies, most of the doctors are affiliated with hospitals of a medical college or university, well known academic centers or tertiary referral centers for the local regions. A limited number of patients travel to specialist centers for 

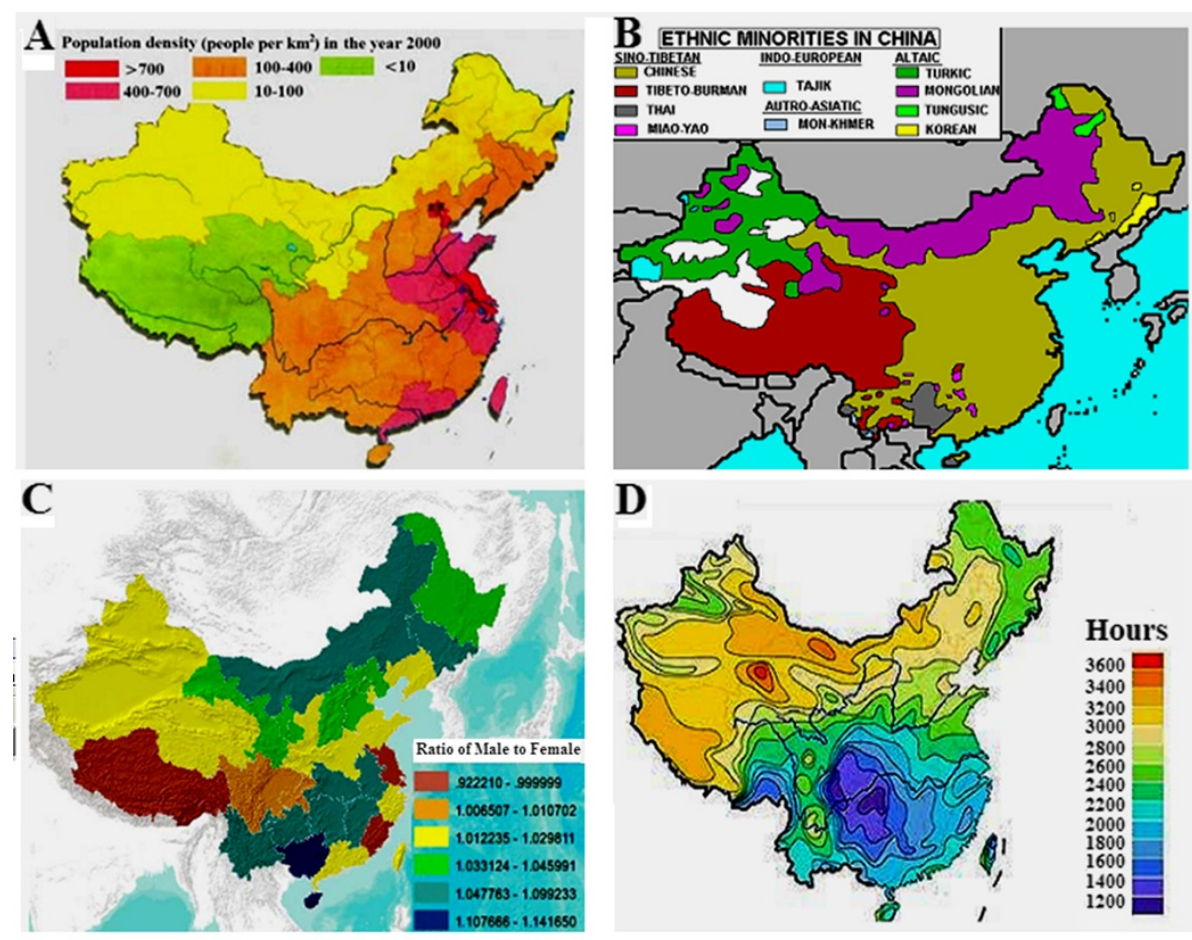

E Annual average temperature of China
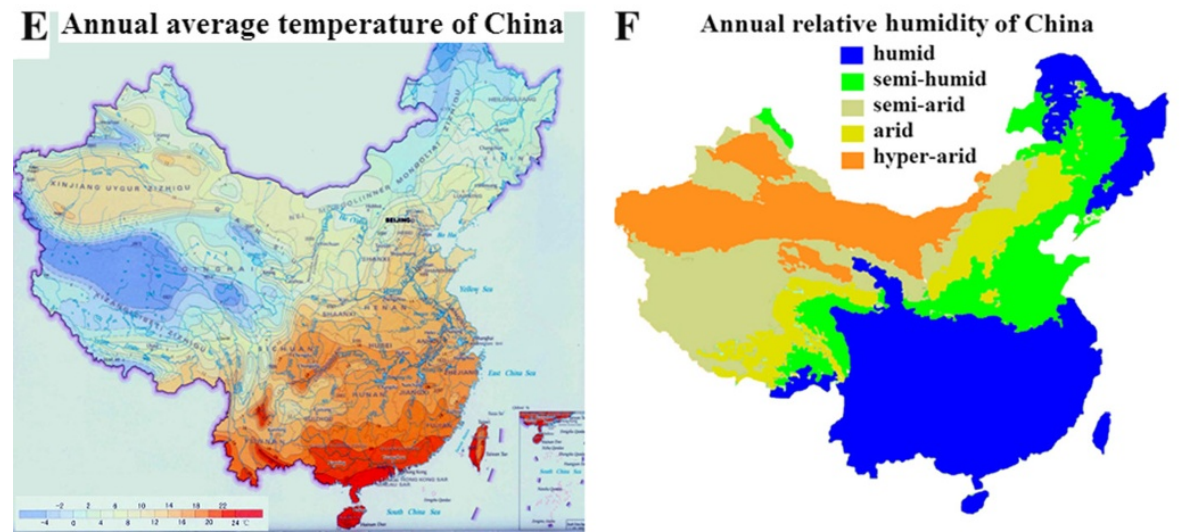

Figure 3 The possible influential factors. Population density of China (A); The distribution of Chinese ethnic groups (B); Ratio of females to males in different regions of China (C); Average sunshine per year in different regions of China (D); Annual average temperature (E); Annual relative humidity of China (F).

examination and treatment. Beijing (in the northern region), Nanjing (in the central region) and Guangzhou (in the southern region) have among the more renowned academic centers for LN in China. Some patients are not treated for glomerular diseases in a few parts of China, and the criteria for renal biopsy are not identical in different centers. These confounding factors limit the validity of the conclusions to some degree, and further studies are needed to provide an accurate estimate of the absolute risk of geographical distribution related the epidemiology of LN in China. These important clinical questions should be addressed by future prospective studies.
Our study is unique in that it involves primarily a Chinese population. The paper falls within the scope of lupus, and the observations increase the knowledge of the epidemiology of biopsy proven-LN in China.

\section{Conclusions}

We summarized the data of the 41 studies of LN disease published in different parts of China and found that geographical distribution appears to be a risk factor for the incidence of biopsy-proven LN in China.

\section{Competing interests}

The authors declare that they have no conflict of interest. 


\section{Authors' contributions}

$Q P, Y L, L Y, Z D, L L$ and YF collected the data and participated in research design. QP, HL and WL participated in data analysis and the writing of the paper. All authors read and approved the final manuscript.

\section{Acknowledgements}

We would like to thank the support of NSFC (NO.81202346), Natural Science Foundation of Guangdong Province, China (NO.S2012040006216), Zhanjiang Planning Project of Science and Technology (NO.2012C3101028 and 2013B01086), Medical Scientific Research Foundation of Guangdong Province, China (NO.B2012284) and Doctoral Fund of Guangdong Medical College and Affiliated Hospital of Guangdong Medical College to Qingjun Pan.

Received: 17 September 2013 Accepted: 26 April 2014 Published: 1 May 2014

\section{References}

1. Rahman A, Isenberg DA: Systemic lupus erythematosus. N Engl J Med 2008, 358(9):929-939.

2. Vasudevan A, Krishnamurthy AN: Changing worldwide epidemiology of systemic lupus erythematosus. Rheum Dis Clin North Am 2010, 36(1):1-13.

3. Borchers AT, Naguwa SM, Shoenfeld Y, Gershwin ME: The geoepidemiology of systemic lupus erythematosus. Autoimmun Rev 2010, 9(5):277-287.

4. Tikly M, Navarra SV: Lupus in the developing world-is it any different? Best Pract Res Clin Rheumatol 2008, 22(4):643-655.

5. Austin HA: Clinical evaluation and monitoring of lupus kidney disease. Lupus 1998, 7(9):618-621

6. Patel M, Clarke AM, Bruce IN, Symmons DP: The prevalence and incidence of biopsy-proven lupus nephritis in the UK: evidence of an ethnic gradient. Arthritis Rheum 2006, 54(9):2963-2969.

7. Ortega LM, Schultz DR, Lenz O, Pardo V, Contreras GN: Review: Lupus nephritis: pathologic features, epidemiology and a guide to therapeutic decisions. Lupus 2010, 19(5):557-574.

8. Bastian HM, Roseman JM, McGwin G Jr, Alarcón GS, Friedman AW, Fessler BJ, Baethge BA, Reveille JD; LUMINA Study Group. LUpus in Mlnority populations: NAture vs nurture: Systemic lupus erythematosus in three ethnic groups. XII. Risk factors for lupus nephritis after diagnosis. Lupus 2002, 11(3):152-160.

9. Seligman VA, Lum RF, Olson JL, Li H, Criswell LA: Demographic differences in the development of lupus nephritis: a retrospective analysis. Am J Med 2002, 112(9):726-729.

10. Kim I, Kim YJ, Kim K, Kang C, Choi CB, Sung YK: Genetic studies of systemic lupus erythematosus in Asia: where are we now? Genes Immun 2009, 10(5):421-432

11. Adler M, Chambers S, Edwards C, Neild G, Isenberg D: An assessment of renal failure in an SLE cohort with special reference to ethnicity, over a 25-year period. Rheumatology 2006, 45(9):1144-1147.

12. Contreras G, Lenz O, Pardo V, Borja E, Cely C, labal K, Nahar N, de La Cuesta C, Hurtado A, Fornoni A, Beltran-Garcia L, Asif A, Young L, Diego J, Zachariah M, Smith-Norwood B: Outcomes in African-Americans and Hispanics with Lupus Nephritis. Kidney Int 2006, 69(10):1846-1851.

13. Korbet SM, Schwartz MM, Evans J, Lewis EJ, Collaborative Study Group: Severe lupus nephritis: racial differences in presentation and outcome. J Am Soc Nephrol 2007, 18(1):244-254.

14. Austin HA 3rd, Boumpas DT, Vaughan EM, Balow JE: High-risk features of lupus nephritis: importance of race and clinical and histological factors in 166 patients. Nephrol Dial Transplant 1995, 10(9):1620-1628.

15. Berden JH: Lupus nephritis. Kidney Int 1997, 52(2):538-558.

16. Churg J, Sobin LH: Renal Disease: Classification and Atlas of Glomerular Disease. Tokyo: Igaku-Shoin; 1982.

17. Churg J, Bernstein J, Glassock RJ: Renal Disease: Classification and Atlas of Glomerular Diseases. 2nd edition. New York: Igaky-Shoin; 1995

18. Xu YZ, Tan DS, Liu HF, Lin HP, Liang D, Huang ZQ: Clinicopathological analysis on 1672 biopsies of glomerular diseases. J Guangdong Med Coll 2009, 27:377-379 (in Chinese).

19. Luo $Q$, Xiong ZB, Xiong ZY, Wang Q, Zhang $Y$, Hou S, et al: Clinicopathological analysis on 615 cases of renal biopsy of adult people. Chin J Integr Tradit West Nephrol 2008, 9:531 (in Chinese).

20. Mo WG, Zeng JJ, Feng ZB, Liao YJ: Analysis of the prevalence and pathological types of 1499 cases of biopsy-proven kidney disease. J Guangxi Med Univ 2004, 21:850-853 (in Chinese).
21. Zhong HB, Huang S, Yu YH, Yang SX, Liao AN, Wang XH: Clinical and pathological features of 913 cases remote mail renal biopsy data. Chin J Integr Trad Wes Nephrol 2007, 8:154-156 (in Chinese).

22. Chen JY, Yuan ZY: Clinicopathological analysis of 269 Renal Biopsies. Mod Med Health 2008, 24:2012-2013 (in Chinese).

23. Zhu CL, Chen YF, Peng HY, Gong Y: Signification of clinicopathological analysis on 100 biopsies of nephritic diseases. Guizhou Med J 2003, 27:345-347 (in Chinese).

24. Li SR, Jiang QH, Chen CS, Hu XM, Shao GJ: Analysis of 113 renal biopsies. Jiangxi Med J 2004, 39:197-198 (in Chinese).

25. Ke YJ, Wu GH, Li YS, Chen YJ, Yang JP, Chen XL, Dai ZY, Gao XF: Clinicopathological analysis of 113 renal biopsies. Chin J Integr Trad Wes Nephrol 2004, 5:546-547 (in Chinese).

26. Xiang $X Q$, Xia YC, Liu YH, Peng YM, Jiang WL, Li J: Comparative analysis of pathology and clinic on 1211 cases of renal biopsy of adult people. J Cent South Univ Technol 2005, 30:733-735. in Chinese.

27. Sun T, Zhao HW, Wu XF, Wang DZ, Li L: Clinical pathological analysis of 489 renal biopsies. Chongqing Med J 2006, 35:934-937 (in Chinese)

28. Shi XD, Chen SF, Hu XQ, Fan DY: Pathological analysis of 669 renal biopsies. Zhejiang Clin Med J 2003, 5:724-725 (in Chinese).

29. Xu YC, Yang Q, Dong DD, Li K: Pathological analysis of 140 renal biopsies. Sichuan Med J 2005, 26:629-631 (in Chinese).

30. Liu K, Chen XY: Analysis of 107 renal biopsies. Appl J Gen Pract 2007 5:384.

31. Yu JP, Yang XY, Cui RL, Yuan WJ: Clinical analysis of 177 percutaneous renal biopsies. Acad J Sec Mil Med univ 2000, 21:800. in Chinese.

32. Chen HP, Zeng $\mathrm{CH}$, Hu WX, Wang QW, Yu YS, Yao XD, Tang Z, Wang JP, Zhu MY, Zhou H, Liu H, Liu ZH, Li LS: Analysis of 10594 renal biopsies data. Chin J Nephrol Dial Transpl 2000, 9:501-509 (in Chinese).

33. Peng YP, Li J, Liu ZW, Yin ST: Clinicopathological analysis on 176 renal biopsies. Anhui Med J 2005, 26:531-532 (in Chinese).

34. Wang T, Liu DG, Shen JQ, Zhou JD: Analysis on cinical pathological data of 805 cases undergoing renal biopsy in part of Jiangsu province. J Southeast Univ (Med Sci) 2010, 29:301-305 (in Chinese).

35. Fan YL, Zhong LM, Lv YX, Wang XL, Meng XH: Clinical application and complications of renal biopsy. Anhui Med J 1995, 16:14 (in Chinese).

36. Du JL, Wang HM, Yu Y, Lian YG, Chen W, Zhang J, Liu YF: Analysis on clinicopathological data of 1542 cases undergoing renal biopsies. Acad J Fourth Mil Med Univ 2006, 27:1599-1602 (in Chinese).

37. Shi J, Liu JH, Tian G: Clinical pathological analysis of 253 renal biopsies. J Pract Med Tech 2010, 17:775-776 (in Chinese)

38. Wang HX, Chen MJ, Wang XY, Wu L: Clinical pathological analysis of 352 renal biopsies. J Chin Phys 2007, 9:1699 (in Chinese).

39. Li SK, Yin ZC, Dai C, Li FC, Zhou SD, Zhang XB, Jin YL: Clinical pathological analysis of 743 renal biopsies. Acta Acad Med Zunyi 2009, 32:473-475 (in Chinese)

40. Wang YT, Xu QY, Guo MH, Zhu TC: Analysis of the prevalence of 919 cases of renal biopsy. Chin J Inte Trad Wes Nephrol 2010, 11:232-234 (in Chinese)

41. Zhao ZZ, Zheng CH, Xiao J, Liu ZS: Clinicopathological analysis on 412 renal biopsies. J Zhengzhou Univ (Med Sci) 2005, 40:368-369.

42. Li XY, Xie QK: Clinicopathological analysis on 144 renal biopsies. Chin Med Eng 2007, 15:735-737 (in Chinese).

43. Zhou SY, Tang XP, Zhang PY, Yue XH, Wang YL: Analysis on 1202 renal biopsies in Ultrastructural pathological diagnosis. J Nat Defending Forces Med Southwest Chin 2008, 29:60 (in Chinese)

44. Zheng CX, Duan LP, Hao HY, Xu L, Liu YF: Clinicopathological analysis on 469 renal biopsies in Handan Area. J Clin Nephrol 2009, 9:74-75 (in Chinese).

45. Huo J, Li RS: Characteristics of the prevalence and pathological data of 1281 cases of renal biopsy in Shanxi Province. Chin J Nephrol 2007, 23:675-676 (in Chinese).

46. Wang YM, Liu ZQ: Analysis of 268 clinical cases of renal biopsy. Med Res Educ 2010, 27:39-40 (in Chinese).

47. Zhao CX, Jia LM, Guo TB, Du ST: Clinicopathological analysis on 190 renal biopsies. Mod J Integrated Tradit Chin Western Med 2009, 18:3610 (in Chinese)

48. Ding XG, Li XD, Gao SL, Guo ZJ: Clinicopathological analysis on 362 renal biopsies. Chin J Mod Med 2008, 18:1905-1909 (in Chinese).

49. Zhang YP, Chen XM, Wu D, Chen QS: Analysis of the prevalence and pathological types of 1954 cases of biopsy-proven kidney disease. J Clin Nephrol 2001, 1:53-59 (in Chinese). 
50. Wang WX, Zhang L, Zhou W, Shi HB: Clinical pathological analysis of 104 renal biopsies. J Clin Med 1996, 16:1-3 (in Chinese).

51. Liu WX: Analysis on clinicopathological data of 100 cases undergoing renal biopsy. World Health Digest 2008, 5:572-574 (in Chinese).

52. Hou XY, Meng YP, Zhao JR: Clinicopathological analysis on 217 renal biopsies in Nei Menggu area. Chin J Integrated Tradit Wes Nephrol 2009, 10:1071 (in Chinese).

53. Wang $\mathrm{CH}$, Yang LH, Ma F, Liu SY, Zhao JM: Composition analysis of 262 renal biopsies of kidney disease. J Clin Nephrol 2009, 9:76 (in Chinese).

54. Li YQ, Wang Y, Li XL, Yao L, Feng JM, Ma JF, Zhang YX, Wang LN: Analysis of 1259 renal biopsy data in Liaoning area. Chin J Mod Med 2006, 16:2830-2833 (in Chinese).

55. Feng W, Liang LQ, Liu Y, Lie CH: Aziguli: pathological analysis of 1500 renal biopsies. J Clin Nephrolo 2008, 8(11):505-507 (in Chinese).

56. Yue H, Zhou J, Adila, He W, Qiao LP, Alinuer, Liu J, Sang XH: Analysis on pathologic data and clinical characteristics of renal biopsy in Uyghur and Han nationalities. Xinjiang Med J 2006, 36:1-3. (in Chinese).

57. Wang LY, Liu SJ, Tian Y: Pathological analysis of $\mathbf{5 0 0}$ renal biopsies. Chin J Lab Diagn 2005, 9:20-21 (in Chinese).

58. Jiang GT, Zhang QQ, An HX, Liu SY: Analysis on pathologic data and clinical characteristics of renal biopsy in Heilongjiang. Hei Longjiang Med J 2008, 32:423 (in Chinese).

59. Nossent JC: Systemic lupus erythematosus on the Caribbean island of Curaçao: an epidemiological investigation. Ann Rheum Dis 1992, 51(11):1197-1201.

60. Al-Maini MH, El-Ageb EM, Al-Wahaibi SS, Al-Farsi Y, Richens ER: Demographic, autoimmune, and clinical profiles of patients with systemic lupus erythematosus in Oman. Rheumatol In 2003, 23(4):186-191.

61. Villamin CA, Navarra SV: Clinical manifestations and clinical syndromes of Filipino patients with systemic lupus erythematosus. Mod Rheumatol 2008, 18(2):161-164.

62. Haiyan W: Nephrology. Thirdth edition. Beijing: People's Medical Publishing House; 2008:1321-1342.

63. Houssiau FA: Management of lupus nephritis: an update. J Am Soc Nephrol 2004, 15(10):2694-2704.

64. Bo H, Yuesi $W$, Guangren $L$ : Variation characteristics of ultraviolet radiation derived from measurement and reconstruction in Beijing, China. Tellus 2010, 62B:100-108.

65. Ke W, Wen C, Ronghui H: Long-term changes of the ultraviolet radiation in China and its relationship with total ozone and precipitation. Adv Atmos Sci 2006, 23(5):700-710.

66. Huali Z, Shilhao X, Delhen T, Dong L, Huafeng L: Seasonal distribution of active systemic lupus erythematosus and its correlation with meteorological factors. Clinic 2011, 66(6):1009-1013.

doi:10.1186/1471-2369-15-67

Cite this article as: Pan et al: Geographical distribution, a risk factor for the incidence of lupus nephritis in China. BMC Nephrology 2014 15:67.

\section{Submit your next manuscript to BioMed Central and take full advantage of:}

- Convenient online submission

- Thorough peer review

- No space constraints or color figure charges

- Immediate publication on acceptance

- Inclusion in PubMed, CAS, Scopus and Google Scholar

- Research which is freely available for redistribution

Submit your manuscript at www.biomedcentral.com/submit
C Biomed Central 